\title{
Chemical Constituents from Leaves of Hydrangea serrata and Their Anti-photoaging Effects on UVB-Irradiated Human Fibroblasts
}

\author{
Ji-Sun Shin, ${ }^{a}$ Hee-Soo Han, ${ }^{a, b}$ Seung-Bin Lee,,${ }^{a, b}$ Da-bin Myung, ${ }^{a, b}$ Keunsuk Lee, ${ }^{c}$ Sun Hee Lee, ${ }^{c}$ \\ Hyoung Ja Kim, ${ }^{*, d}$ and Kyung-Tae Lee*,a,b \\ ${ }^{a}$ Department of Pharmaceutical Biochemistry, College of Pharmacy, Kyung Hee University; Seoul 02447, Republic of \\ Korea: ${ }^{b}$ Department of Life and Nanopharmaceutical Sciences, College of Pharmacy, Kyung Hee University; Seoul \\ 02447, Republic of Korea: ${ }^{c}$ Department of New Material Development, COSMAXBIO; Gyeonggi 13486, Republic of \\ Korea: and ${ }^{d}$ Molecular Recognition Research Center, Materials and Life Science Research Division, Korea Institute \\ of Science and Technology; Seoul 02792, Republic of Korea. \\ Received September 25, 2018; accepted November 28, 2018
}

\begin{abstract}
Hydrangea serrata (Thunb.) Ser. (Hydrangeaceae) leaves have been used as herbal teas in Korea and Japan. The objective of this study was to identify anti-photoaging compounds in aqueous EtOH extract prepared from leaves of $\mathrm{H}$. serrata and their effects on UVB-irradiated Hs68 human foreskin fibroblasts. Phytochemical study on $\boldsymbol{H}$. serrata leaves led to the isolation and characterization of ten compounds: hydrangenol, thunberginol $A$, thunberginol $C$, hydrangenoside $A$, hydrangenoside $C$, cudrabibenzyl A, 2,3,4'-trihydroxystilbene, thunberginol $\mathrm{F}$, quercetin 3-O- $\beta$-D-xylopyranosyl (1-2)- $\beta$-D-galactopyranoside, quercetin 3-O- $\beta$-Dxylopyranosyl (1-2)- $\beta$-D-glucopyranoside. Cudrabibenzyl A, 2,3,4'-trihydroxystilbene, quercetin 3-O- $\beta$-Dxylopyranosyl (1-2)- $\beta$-D-galactopyranoside, quercetin $3-O-\beta$-D-xylopyranosyl (1-2)- $\beta$-D-glucopyranoside were firstly isolated from $\mathrm{H}$. serrata. We estimated the effects of 10 compounds on cell viability and production of pro-collagen Type I, matrix metalloproteinase (MMP)-1, and hyaluronic acid (HA) after UVB irradiation. Of these compounds, hydrangenol showed potent preventive activities against reduced cell viability and degradation of pro-collagen Type I in UVB-irradiated Hs68 fibroblasts. Hydrangenol had outstanding inductive activities on HA production. It suppressed mRNA expression levels of MMP-1, MMP-3, hyaluronidase (HYAL)-1, HYAL-2, cyclooxygenase-2 (COX-2), interleukin (IL)-6, IL-8, and IL-1 $\beta$ in UVB-irradiated Hs68 fibroblasts. When Hs68 fibroblasts were exposed to hydrangenol after UVB irradiation, UVB-induced reactive oxygen species (ROS) production was suppressed. Hydrangenol also inhibited the activation of activator protein-1 (AP-1) and signal transduction and activation of transcription 1 (STAT-1) by downregulating phosphorylation of p38 and extracellular signal-regulated kinase (ERK). Our data indicate that hydrangenol isolated from $\boldsymbol{H}$. serrata leaves has potential protective effects on UVB-induced skin photoaging.
\end{abstract}

Key words Hydrangea serrata; photoaging; matrix metalloproteinase (MMP); procollagen type 1; skin fibroblast

\section{INTRODUCTION}

Human skin comprises the epidermis, dermis, and hypodermis. The epidermal extracellular matrix is a basement membrane composed of keratinocytes that produce keratins. The dermis is composed of fibrous structural collagen-rich extracellular matrix (ECM) which is essentially responsible for the skin's tensile strength and mechanical properties, together with elastin and hyaluronic acid. ${ }^{1,2)}$ Upon exposure to solar UV, especially UVB, degradation of ECM is being processed through activation of matrix metalloproteinases (MMPs) with decreased pro-collagen synthesis, resulting in wrinkle formation and sagging skin (skin photoaging). ${ }^{3)}$ A great number of plant extracts and phytochemicals including polyphenols (flavonoids and non-flavonoids) and non-phenolic derivatives possess anti-oxidant and anti-inflammatory properties. They have received growing attention as potential dietary supplements for anti-aging interventions. ${ }^{4,5)}$ Natural sources of photoprotective phytochemicals including green tea, coffee, berries, and pomegranate have been reported. ${ }^{5,6)}$

Hydrangea (Hydrangeaceae) leaves have been consumed as medicine and tea in far-east Asian countries such as Korea, China, and Japan. ${ }^{7)}$ Some researchers have reported that ex- tracts of hydrangea leaves possess anti-inflammatory, ${ }^{8)}$ hepatoprotective, ${ }^{9)}$ and antimalarial activities. ${ }^{10)}$ To date, a number of bioactive compounds such as dihydroisocoumarins, secoiridoids, and stilbenes (hydrangenol, phyllodulcin, macrophylloside, and their glucosides) have been isolated from hydrangea plants. ${ }^{11,12)}$ Phyllodulcin has been identified as the compound responsible for the sweet taste of its infusion." Hydrangea serrata (Thunb.) Ser. is native to Korean mountains known as "San-soogook, Mountain Hydrangea, or Tea of Heaven." $H$. serrata is small deciduous shrubs similar to $H$. macrophylla and usually with lace cap flowers that are flat with smaller florets in the center surrounded by larger florets. The blooms are either blue or pink depending on the acidity of the soil. The flowers will be blue in higher acidic soils and lilac to pink in alkaline soils. Growing to $1-2 \mathrm{~m}$ tall and broad, it features dark green, serrated (toothed), and ovate leaves to $15 \mathrm{~cm}$ long. ${ }^{13-15)}$ Its leaves are used to make herbal teas. However, few studies have determined the chemical compositions of $H$. serrata and their anti-photoaging activities. Therefore, the objective of this study was to isolate constituents from $\mathrm{H}$. serrata and determine their anti-photoaging properties in UVBirritated skin fibroblast. 


\section{MATERIALS AND METHODS}

Isolation of Compounds from Ethanol Extracts from $\boldsymbol{H}$. serrata Leaves The leaves of Hydrangea serrata (THunB.) SER. $(20 \mathrm{~g})$ were extracted twice with 50 or $70 \%$ ethanol $(375 \mathrm{~mL})$ at $50^{\circ} \mathrm{C}$ for $3 \mathrm{~h}$ to give dried extract residue $50 \%$ ethanol extracts from $H$. serrata (EHS50, 5.8g, 29\%) and $70 \%$ ethanol extracts from H. serrata (EHS70, 5.6 g, 28\%), respectively. EHS70 was fractionated on Diaion HP-20 column, starting with $30 \% \mathrm{MeOH}$ followed by $50 \%(50 \mathrm{M}), 70 \%$ (70M), $100 \% \mathrm{MeOH}(100 \mathrm{M})$ and $\mathrm{CH}_{2} \mathrm{Cl}_{2}-\mathrm{MeOH}(\mathrm{CM}), 1: 1$ as an eluent. Fraction $70 \mathrm{E}-100 \mathrm{M}$ was subjected to sephadex LH-20 CC eluted with $\mathrm{MeOH}$ to afford seven fractions (70E100M1-70E100M7). Subfraction 70E100M4 was further purified by toyopearl HW-40 eluted with $\mathrm{MeOH}$ to give hydrangenol $(31.1 \mathrm{mg})$. Fraction $70 \mathrm{E}-70 \mathrm{M}$ was subjected to silica gel $\mathrm{CC}$ using $\mathrm{CH}_{2} \mathrm{Cl}_{2}-\mathrm{MeOH}$ (7:1) mixtures to give nine fractions (70E70M1-70E70M9). Subfraction 70E70M2 was further purified by preparative HPLC using a gradient mobile phase system $\mathrm{CH}_{3} \mathrm{CN}-\mathrm{H}_{2} \mathrm{O}(30: 70-70: 30$, v/v) at flow rate $4 \mathrm{~mL} / \mathrm{min}$ to give hydrangenoside $\mathrm{A}\left(24.8 \mathrm{mg}, t_{\mathrm{R}}=25 \mathrm{~min}\right)$ and hydrangenoside $\mathrm{C}\left(2.7 \mathrm{mg}, t_{\mathrm{R}}=28 \mathrm{~min}\right)$. Preparative HPLC was performed on a Waters pump (model 1525) with photodiode array detector (Waters model 2996) using a Luna C18 $(10 \mathrm{~mm} \times 250 \mathrm{~mm}$, Phenomenex $)$ column. Fraction $70 \mathrm{E}-50 \mathrm{M}$ was separated by silica gel eluted with $\mathrm{CH}_{2} \mathrm{Cl}_{2}-\mathrm{MeOH}-\mathrm{H}_{2} \mathrm{O}$ $(4: 1.2: 0.1)$ to give ten fractions (70E50M1-70E50M10). Subfraction 70E50M9 (38.7 mg) was purified by preparative HPLC using $32 \% \mathrm{MeOH}$ to give cudrabibenzyl A $\left(4.8 \mathrm{mg}, t_{\mathrm{R}}=3.5 \mathrm{~min}\right)$, quercetin $3-O-\beta$-D-xylopyranosyl (1-2)- $\beta$-D-galactopyranoside (quercetin-xylo-galato, $8.4 \mathrm{mg}$, $\left.t_{\mathrm{R}}=21 \mathrm{~min}\right)$ and quercetin $3-O-\beta$-D-xylopyranosyl (1-2)- $\beta$-Dglucopyranoside (quercetin-xylo-gluco, $5.3 \mathrm{mg}, t_{\mathrm{R}}=23 \mathrm{~min}$ ). EHS50 was fractionated on Diaion HP-20 column, starting with $30 \% \mathrm{MeOH}$ followed by $50 \%$ (50M), 70\% (70M), $100 \% \mathrm{MeOH}(100 \mathrm{M})$ and $\mathrm{CH}_{2} \mathrm{Cl}_{2}-\mathrm{MeOH}(\mathrm{CM}), 1: 1$ as an eluent. Fraction $50 \mathrm{E}-100 \mathrm{M}(731.1 \mathrm{mg})$ was subjected to sephadex $\mathrm{LH}-20 \mathrm{CC}$ eluted with $\mathrm{MeOH}$ to afford five fractions (50E100M1-50E100M5). Subfraction 50E100M4 was further purified by preparative HPLC using a gradient mobile phase system $\mathrm{CH}_{3} \mathrm{CN}-\mathrm{H}_{2} \mathrm{O}(20: 70 \rightarrow 75: 25$, v/v) as described above to give hydrangenol $\left(29.1 \mathrm{mg}, t_{\mathrm{R}}=24 \mathrm{~min}\right)$, thunberginol $\mathrm{A}$ $\left(2.5 \mathrm{mg}, t_{\mathrm{R}}=22 \mathrm{~min}\right)$, thunberginol $\mathrm{C}\left(18.1 \mathrm{mg}, t_{\mathrm{R}}=17 \mathrm{~min}\right)$, $2,3,4^{\prime}$-trihydroxystilbene $\left(1.5 \mathrm{mg}, t_{\mathrm{R}}=8.2 \mathrm{~min}\right)$ and thunberginol F (4.3 mg, $\left.t_{\mathrm{R}}=15.3 \mathrm{~min}\right)$.

Cell Culture and UVB Exposure Human skin fibroblast Hs68 cells were obtained from the American Type Culture Collection (ATCC, Manassas, VA, U.S.A.). Cells were grown in Dulbecco's modified Eagle's medium (DMEM) containing $10 \%$ fetal bovine serum (FBS) and penicillin-streptomycin sulfate ( $100 \mathrm{units} / \mathrm{mL}$ and $100 \mu \mathrm{g} / \mathrm{mL}$ ) in a humidified atmosphere of $5 \% \mathrm{CO}_{2}$. Hs 68 cells were plated at $1 \times 10^{5}$ cells $/ \mathrm{mL}$ in culture vessels and incubated overnight. Cells were then washed with phosphate-buffered saline (PBS) and irradiated with UVB at $15 \mathrm{~mJ} / \mathrm{cm}^{2}$ using UVP Crosslinker (Analytik Jena AG, Jena, Germany). Cells were washed with PBS and further incubated in fresh DMEM in the presence or absence of the indicated concentration of compounds. Isolated compounds were dissolved in dimethyl sulfoxide (DMSO).

Determination of Cell Viability After UVB irradiation, cells were treated with indicated concentration of compounds for $24 \mathrm{~h}$. Epigallocatechin gallate (EGCG, $10 \mu \mathrm{M})$ was used as a positive control. ${ }^{16)}$ Fifty microliters of 3-(4,5-dimethylthiazol-2-yl)-2,5-diphenyltetrazolium bromide (MTT) was then added to the wells followed by for $4 \mathrm{~h}$. Formazan crystals were completely dissolved by DMSO and the optical density at $595 \mathrm{~nm}$ was measured using a microplate reader (Molecular Devices, U.S.A.).

Enzyme-Linked Immunosorbent Assays (ELISAs) for Pro-collagen Type I, Matrix Metalloproteinase (MMP)-1, Hyaluronic Acid (HA) Following UVB irradiation, cells were treated indicated the concentration of compounds for $24 \mathrm{~h}$. EGCG $(10 \mu \mathrm{M})$ was used as a positive control for type I procollagen and MMP-1. ${ }^{16)}$ The level of pro-collagen type I, MMP-1, hyaluronic acid in culture media was determined using specific ELISA kit (Procollagen Type I C-Peptide ELISA Kit, TaKaRa, Shiga, Japan; human MMP-1 ELISA kit, Abcam, Cambridge, UK; HA ELISA kit, R\&D Systems, MN, U.S.A.).

RNA Preparation and Real-Time Quantitative (q)RTPCR Total cellular RNA from compound-treated cells was isolated using Easy Blue ${ }^{\circledR}$ kits (Intron Biotechnology, Seoul, Korea) and cDNA was prepared using random oligonucleotide primers (Promega, Madison, WI, U.S.A.) and TOPscript ${ }^{\mathrm{TM}}$ cDNA synthesis kit (Enzynomics, Daejeon, Korea). PCR amplification was performed using the incorporation of SYBR green (TaKaRa, Shiga, Japan) and specific primers. Specific gene primer was listed in Supplementary Table 1. Steady-state mRNA levels of MMP-1, MMP-3, HA synthase (HAS) 2, hyaluronidase (HYAL)-1, HYAL-2, cyclooxygenase-2 (COX-2), interleukin (IL)-6, IL-8, IL-1 $\beta$, and glyceraldehyde-3-phosphate dehydrogenase (GAPDH) were determined by real-time PCR using the Light Cycler1.5 (TaKaRa, Shiga, Japan). Dissociation curve analysis for MMPs and $\beta$-actin oligos showed a single peak for each. Mean $C_{\mathrm{t}}$ values of genes of interest were calculated from triplicate measurements and normalized versus the mean $C_{\mathrm{t}}$ of GAPDH.

Western Blot Analysis Total proteins from compoundtreated cells were isolated using PRO-PREP (Intron Biotechnology, Seoul, Korea) and incubated at $4{ }^{\circ} \mathrm{C}$ for $30 \mathrm{~min}$. Cell debris was removed by microcentrifugation, followed by quick freezing of the supernatants. Nuclear extracts from compound-treated cells were prepared using a hypotonic buffer and high salt buffer. Cell pellets were resuspended in hypotonic buffer (10 mM $N$-(2-hydroxyethyl)piperazine- $N^{\prime}-2$ ethanesulfonic acid (HEPES), $\mathrm{pH} 7.9,1.5 \mathrm{mM} \mathrm{MgCl} 2,10 \mathrm{mM}$ $\mathrm{KCl}, 0.2 \mathrm{mM}$ phenylmethylsulfonyl fluoride (PMSF), $0.5 \mathrm{mM}$ dithiothreitol (DTT), $10 \mu \mathrm{g} / \mathrm{mL}$ aprotinin) and incubated on ice for $15 \mathrm{~min}$. Cells were then lysed by adding $0.1 \%$ Nonidet P-40 and vortexed vigorously for $10 \mathrm{~s}$. Nuclei were pelleted by centrifugation at $12000 \times \boldsymbol{g}$ for $1 \mathrm{~min}$ at $4^{\circ} \mathrm{C}$ and resuspended in high salt buffer (20mM HEPES, pH 7.9, 25\% glycerol, $400 \mathrm{mM} \mathrm{KCl}, 1.5 \mathrm{mM} \mathrm{MgCl}_{2}, 0.2 \mathrm{mM}$ ethylenediaminetetraacetic acid (EDTA), $0.5 \mathrm{mM}$ DTT, $1 \mathrm{mM} \mathrm{NaF}, 1 \mathrm{mM}$ sodium orthovanadate). The protein concentration of the lysates was determined using the Bio-Rad protein assay reagent.

Determination of Reactive Oxygen Species (ROS) Generation The generation of ROS was estimated using the redox-sensitive fluorescent dye fluorescent probes $2^{\prime}, 7^{\prime}$-dichlorodihydrofluorescein diacetate $\left(\mathrm{H}_{2} \mathrm{DCFDA}\right)$. Following UVB irradiation, cells were treated with hydrangenol for indicated time, and further incubated with $20 \mu \mathrm{M} \mathrm{H}_{2}$ DCFDA for $30 \mathrm{~min}$. 
<smiles>O=C1OC(c2ccc(O)cc2)Cc2cccc(O)c21</smiles>

hydrangenol<smiles>O=c1oc(-c2ccc(O)c(O)c2)cc2cccc(O)c12</smiles><smiles>O=C1OC(c2ccc(O)cc2)Cc2cc(O)cc(O)c21</smiles>

thunberginol $\mathrm{C}$

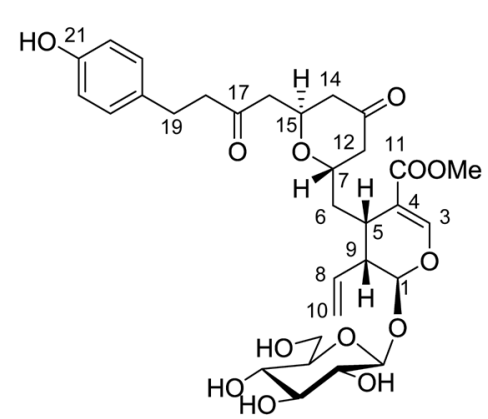

hydrangenoside $A$

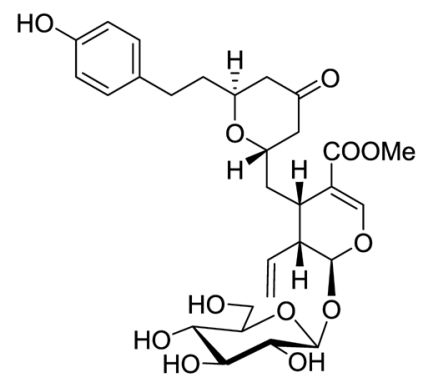

hydrangenoside C<smiles>O=C(O)c1c(O)cc(OC2OCC(O)C(O)C(O)C2O)cc1CCc1ccc(O)cc1</smiles><smiles>Oc1ccc(C=Cc2cccc(O)c2O)cc1</smiles>

2,3,4'-trihydroxystilbene<smiles>O=C1OC(=Cc2ccc(O)c(O)c2)c2c(O)cccc21</smiles>

thunberginol $F$

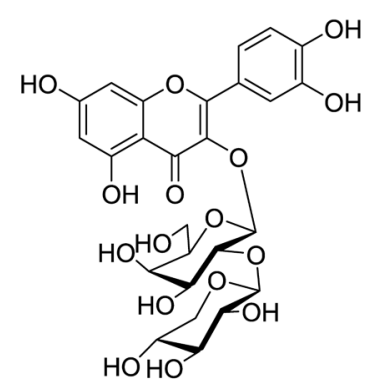

quercetin 3-O- $\beta-D-x y l o p y r a n o s y l$ (1-2)- $\beta$-D-galactopyranoside

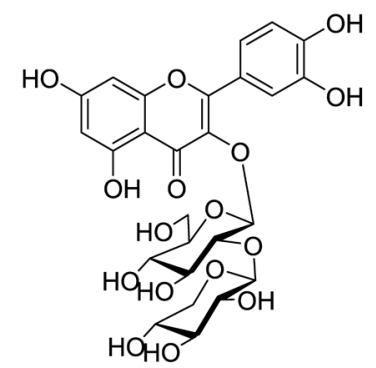

quercetin 3-O- $\beta$-D-xylopyranosyl (1-2)- $\beta$-D-glucopyranoside

Fig. 1. Structures of Ten Compounds Isolated from the Leaves of Hydrangea serrata

Then, cells were resuspended in PBS and the fluorescence signal analyzed using flow cytometry (Beckman Coulter Inc., Brea, CA, U.S.A.).

Statistical Analysis Results are expressed as the mean \pm standard deviation (S.D.) of triplicate experiments with similar patterns. The band density was estimated using Quantity One ${ }^{\circledR}$ program (Bio-Rad Laboratories, CA, U.S.A.). Statistically significant values were compared using ANOVA and Dunnett's post-hoc test, and p-values of less than 0.05 were considered statistically significant. ${ }^{\#} p<0.05$ compared with the control group, and $* p<0.05$, ** $p<0.01$, $* * * p<0.001$ compared with the UVB-irradiated group.

\section{RESULTS AND DISCUSSION}

Chemical investigation of aqueous EtOH extracts of $H$. serrata leaves resulted in the isolation and identification of ten compounds; dihydroisocoumarins (hydrangenol, thunberginol
A, thunberginol C), secoiridoid glucosides (hydrangenoside A and hydrangenoside $\mathrm{C}$ ), bibenzyl derivatives (cudrabibenzyl $\mathrm{A}$ and 2,3,4'-trihydroxystilbene), phthalide (thunberginol $\mathrm{F}$ ) and flavonoid glycosides (quercetin 3-O- $\beta$-D-xylopyranosyl (1-2)- $\beta$-D-galactopyranoside (quercetin-xylo-galato), quercetin 3- $O$ - $\beta$-D-xylopyranosyl (1-2)- $\beta$-D-glucopyranoside (quercetinxylo-gluco)) (Fig. 1, Supplementary data 1). It is the first time that compounds cudrabibenzyl A, 2,3,4'-trihydroxystilbene, quercetin-xylo-galato, and quercetin-xylo-gluco were isolated from leaves of $H$. serrata. Hydrangenol was determined as the main ingredient using an HPLC/UV system with an analytical $\mathrm{C}_{18}$ column, and its content in 50 and $70 \%$ ethanol extracts was found to be 1.14 and $1.02 \%$ from HPLC profiles, respectively, while other isolates could not be measured due to low content and overlap with the others. Also, the content of hydrangenol in water extract $\left(60^{\circ} \mathrm{C}\right)$ was found to be $0.08 \%$ by our extraction conditions (Supplementary data 1-S45). To determine whether isolated ten compounds might possess anti- 
Table 1. Effects of Compounds Isolated from Hydrangea serrata on Cell Viability and Pro-collagen Type I Productions in UVB-Irradiated Hs68 Cells

\begin{tabular}{|c|c|c|}
\hline Compounds ( $1 \mu \mathrm{M})$ & Cell viability (\%) & $\begin{array}{l}\text { Pro-collagen type I } \\
(\mathrm{ng} / \mathrm{mL})\end{array}$ \\
\hline Control & $100.00 \pm 1.19$ & $\begin{array}{r}725.99 \pm 46.13 \\
(100 \pm 6.35)^{a)}\end{array}$ \\
\hline UV & $88.47 \pm 4.86^{\#}$ & $\begin{array}{l}460.13 \pm 22.02^{\#} \\
(63.38 \pm 3.03)^{\#}\end{array}$ \\
\hline Hydrangenol & $98.6 \pm 2.57 * * *$ & $\begin{array}{l}519.32 \pm 25.60 * \\
(71.53 \pm 3.53)^{*}\end{array}$ \\
\hline Thunberginol A & $97.07 \pm 0.98 * *$ & $\begin{array}{l}562.46 \pm 28.18 * * * \\
(77.47 \pm 3.88)^{* * *}\end{array}$ \\
\hline Thunberginol $\mathrm{C}$ & $105.92 \pm 2.52 * * *$ & $\begin{array}{c}557.53 \pm 44.90 * * \\
(76.80 \pm 6.18)^{* *}\end{array}$ \\
\hline Hydrangenoside A & $88.92 \pm 0.20$ & $\begin{array}{l}573.56 \pm 21.46 * * * \\
(79.00 \pm 2.96)^{* * * *}\end{array}$ \\
\hline Hydrangenoside C & $93.12 \pm 0.16$ & $\begin{array}{c}557.77 \pm 10.66 * * * \\
(76.83 \pm 1.47)^{* * *}\end{array}$ \\
\hline Cudrabibenzyl A & $94.69 \pm 5.20 *$ & $\begin{array}{c}495.98 \pm 49.49 \\
(68.32 \pm 6.82)\end{array}$ \\
\hline 2,3,4'-Trihydroxystilbene & $97.17 \pm 3.54 * *$ & $\begin{array}{l}553.03 \pm 1.30 * * * \\
(76.18 \pm 0.18)^{* * *}\end{array}$ \\
\hline Thunberginol F & $104.07 \pm 1.74 * * *$ & $\begin{array}{l}572.44 \pm 80.48^{*} \\
(78.85 \pm 11.09)^{*}\end{array}$ \\
\hline Quercetin-xylo-galato & $95.35 \pm 2.59 *$ & $\begin{array}{c}476.87 \pm 48.66 \\
(65.69 \pm 6.70)\end{array}$ \\
\hline Quercetin-xylo-gluco & $104.41 \pm 1.58 * * *$ & $\begin{array}{c}528.25 \pm 33.63 * \\
(72.76 \pm 4.63)^{*}\end{array}$ \\
\hline EGCG $(10 \mu \mathrm{M})$ & $93.45 \pm 2.50 * * *$ & $\begin{array}{c}514.57 \pm 10.66^{*} \\
(70.88 \pm 1.47)^{*}\end{array}$ \\
\hline
\end{tabular}

a) Numbers in marks of parenthesis indicated the percent (\%).

photoaging properties, we assessed their effects on cell viability and productions of pro-collagen type I, MMP-1, and HA in UVB-irritated Hs68 skin fibroblasts. EGCG $(10 \mu \mathrm{M})$ was used as a positive control for cell viability, type I procollagen, and MMP-1. ${ }^{16)}$

Cytoprotective effects of ten compounds were evaluated using MTT assay. Hs68 cells were exposed to UVB $\left(15 \mathrm{~mJ} / \mathrm{cm}^{2}\right)$ and then treated with ten compounds at $1 \mu \mathrm{M}$ for $24 \mathrm{~h}$. Cell viability was significantly decreased $(88.77 \%)$ after UVB-irradiation compared to that of control cells (100\%). The eight compounds except hydrangenoside A and hydrangenoside $\mathrm{C}$ significantly recovered the reduction in cell viability induced by UVB irradiation (Table 1).

Accumulating data suggest that photoaging skin is characterized by a reduction in the deposition of collagen fibers which may be resulted from increased collagen degradation. ${ }^{17)}$ To evaluate the effects of ten compounds on collagen production in UVB-irradiated Hs68 fibroblasts, UVB-irradiated cells were treated with ten compounds for $24 \mathrm{~h}$ and type I procollagen production in cell supernatant was measured by ELISA. UVB exposure decreased pro-collagen type I production by $36.62 \%$, while eight compounds except cudrabibenzyl A and quercetin-xylo-galato recovered UVB-induced reduction of pro-collagen type I by 22.26 to $42.67 \%$ (Table 1 ).

MMP-1 is a major protein-degrading enzyme in human skin that can fragment native fibrillar collagens, predominantly type I and III collagens. ${ }^{18)}$ The fragments then become unfolded and degraded by MMP-2, -9 , and $-3 .{ }^{19)}$ Therefore,
Table 2. Effects of Compounds Isolated from Hydrangea serrata on MMP-1 and Hyaluronic Acid Productions in UVB-Irradiated Hs68 Cells

\begin{tabular}{|c|c|c|}
\hline Compounds ( $1 \mu \mathrm{M})$ & MMP-1 (ng/mL) & Hyaluronic acid (ng/mL) \\
\hline Control & $\begin{array}{l}1.45 \pm 0.52 \\
(100 \pm 35.86)\end{array}$ & $\begin{array}{r}883.85 \pm 155.53 \\
(100 \pm 17.60)\end{array}$ \\
\hline UV & $\begin{array}{c}5.70 \pm 0.39^{\#} \\
(396.10 \pm 26.90)\end{array}$ & $\begin{array}{c}515.22 \pm 92.84^{\#} \\
(58.29 \pm 10.50)\end{array}$ \\
\hline Hydrangenol & $\begin{array}{c}2.51 \pm 0.03 * * * \\
(173.10 \pm 2.07)^{* * *}\end{array}$ & $\begin{array}{l}1045.38 \pm 118.14^{* * * *} \\
(118.28 \pm 13.37)\end{array}$ \\
\hline Thunberginol A & $\begin{array}{c}2.74 \pm 0.04 * * * \\
(188.97 \pm 2.76)^{* * *}\end{array}$ & $\begin{array}{c}629.74 \pm 12.10 \\
(71.25 \pm 1.37)\end{array}$ \\
\hline Thunberginol $\mathrm{C}$ & $\begin{array}{c}1.58 \pm 0.05 * * * \\
(108.97 \pm 3.45)^{* * *}\end{array}$ & $\begin{array}{c}711.87 \pm 149.17 \\
(80.54 \pm 16.88)\end{array}$ \\
\hline Hydrangenoside A & $\begin{array}{c}1.84 \pm 0.01 * * * \\
(126.90 \pm 0.69)^{* * *}\end{array}$ & $\begin{array}{c}794.64 \pm 156.29 * \\
(89.91 \pm 17.68)\end{array}$ \\
\hline Hydrangenoside C & $\begin{array}{c}2.40 \pm 0.03 * * * \\
(165.52 \pm 2.07)^{* * *}\end{array}$ & $\begin{array}{l}893.44 \pm 174.16^{* * *} \\
(101.09 \pm 19.70)\end{array}$ \\
\hline Cudrabibenzyl A & $\begin{array}{c}2.51 \pm 0.01 * * * \\
(173.10 \pm 0.69)^{* * *}\end{array}$ & $\begin{array}{c}485.14 \pm 76.18 \\
(54.89 \pm 8.62)\end{array}$ \\
\hline 2,3,4'-Trihydroxystilbene & $\begin{array}{c}1.87 \pm 0.01 * * * \\
(128.97 \pm 0.69)^{* * *}\end{array}$ & $\begin{array}{c}551.42 \pm 39.85 \\
(62.39 \pm 4.51)\end{array}$ \\
\hline Thunberginol F & $\begin{array}{c}1.47 \pm 0.07 * * * \\
(101.38 \pm 4.83)^{* * *}\end{array}$ & $\begin{array}{c}492.61 \pm 48.82 \\
(55.73 \pm 5.52)\end{array}$ \\
\hline Quercetin-xylo-galato & $\begin{array}{c}3.24 \pm 0.02 * * * \\
(223.45 \pm 1.38)^{* * *}\end{array}$ & $\begin{array}{l}834.43 \pm 133.09 * * \\
(94.41 \pm 15.06)\end{array}$ \\
\hline Quercetin-xylo-gluco & $\begin{array}{c}1.73 \pm 0.01 * * * \\
(119.31 \pm 0.69)^{* * *}\end{array}$ & $\begin{array}{c}714.56 \pm 171.52 \\
(80.85 \pm 19.41)\end{array}$ \\
\hline EGCG $(10 \mu \mathrm{M})$ & $\begin{array}{c}0.14 \pm 0.01 * * * \\
(9.66 \pm 0.69)^{* * *}\end{array}$ & \\
\hline
\end{tabular}

a) Numbers in marks of parenthesis indicated the percent (\%).

MMPs are key coordinators for the formation of wrinkles in the photoaging process. ${ }^{20)}$ Interestingly, all compounds had potent effects on MMP-1 production in UVB-irradiated Hs68 fibroblasts (Table 2). Compounds except quercetin-xylo-gluco inhibited UVB-induced MMP-1 production by more than $50 \%$ at $1 \mu \mathrm{M}$.

HA, another key component of dermal ECM, controls skin functions such as skin hydration, turgidity, elasticity, and diffusion of metabolites and nutrients. ${ }^{21,22)} \mathrm{HA}$ is synthesized by three HAS and catabolized by several HYAL enzymes. ${ }^{23)}$ Loss of HA has been associated with skin aging and UVB exposure causes loss of HA because of down-regulated HAS expression. ${ }^{224)}$ We evaluated the effects of isolated compounds on the UVB-induced loss of HA by ELISA. UVB exposure decreased HA production by $41.68 \%$, while hydrangenol, hydrangenoside $\mathrm{A}$, hydrangenoside $\mathrm{C}$, and quercetin-xylo-galato significantly recovered UVB-induced HA loss. Of them, hydrangenol was the most potent inducer of HA (Table 2).

We further examined the protective effect of hydrangenol on UVB-irradiated Hs68 fibroblasts and the underlying molecular mechanism. To elucidate the mechanism of hydrangenol for pro-collagen type I recovery, we determined effects of hydrangenol $(1.5,3$, or $6 \mu \mathrm{M})$ on mRNA expression of collagen type $1 \alpha 1$ chain (COL1A1), a major component of collagen type I, by qRT-PCR. The mRNA expression of COL1A1 was significantly reduced by UVB irradiation, but hydrangenol treatment failed to recover such reduction (data not shown). Therefore, increased production of pro-collagen type I by hydrangenol might be related to collagen degradation decreases 

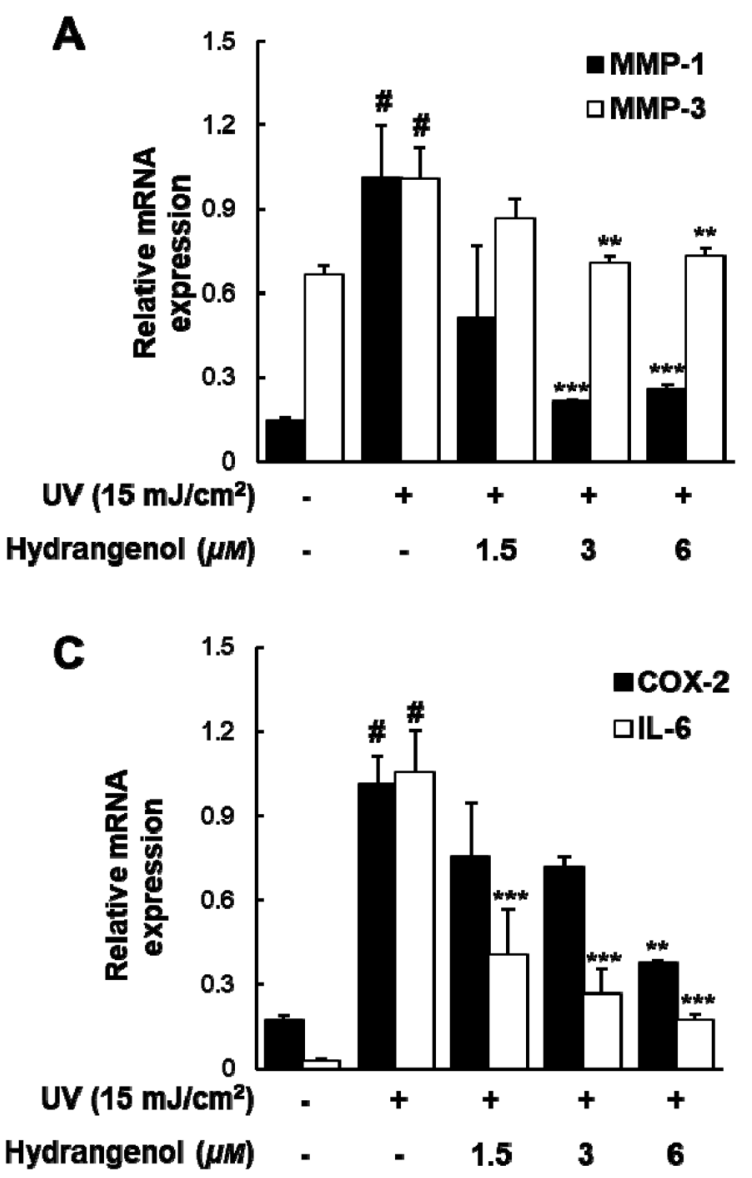

B

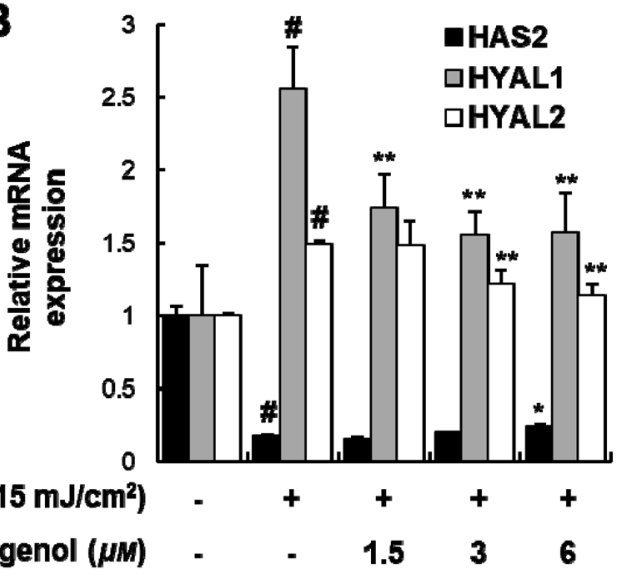

D

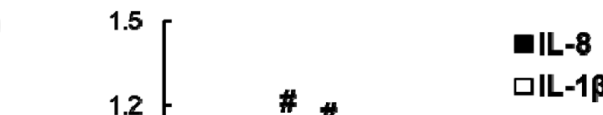

Fig. 2. Effects of Hydrangenol on mRNA Expressions of MMP-1, MMP-3, HAS-2, HYAL-1, HYAL-2, COX-2, IL-6, IL-8, and IL-1 $\beta$ in UVBIrradiated Hs68 Cells

Cells were exposed to UVB and treated with hydrangenol for $6 \mathrm{~h}$. Then mRNA expressions of MMP-1 and MMP-3 (A), HAS-2, HYAL-1, and HYAL-2 (B), COX-2 and IL-6 (C), and IL-8 and IL-1 $\beta$ (D) were determined by qRT-PCR using specific primers and normalized against GAPDH. Data are presented as means \pm S.D.s of three independent experiments. ${ }^{*} p<0.05$ vs. the control cells; $* p<0.05, * * p<0.01, * * * p<0.001 v s$. UVB-exposed cells.

rather than collagen synthesis upregulation. It has been reported that collagen is fragmented by MMP-1 from a single site in its central triple. MMP-3 not only degrades ECM components, but also activates pro MMP-1. ${ }^{18,19)}$ Based on the significant inhibitory effect of hydrangenol on UVB-induced MMP-1 production, we examined effects of hydrangenol at different concentrations $(1.5,3$, or $6 \mu \mathrm{M})$ on MMP-1 and MMP-3 mRNA expression in UVB-irradiated Hs68 fibroblasts. Hydrangenol concentration-dependently reduced UVB-induced MMP-1 and MMP-3 mRNA expression (Fig. 2A). These results suggest that hydrangenol can potently recover UVB-induced collagen disruption by down-regulating expression of MMPs.

We investigated whether the recovery effect of hydrangenol on HA production might be related to HA metabolism by determining mRNA expression levels of HAS and HYALs. Results showed that mRNA expression levels of HAS-2 were significantly reduced in UVB-irradiated cells while those of HYAL-1 and HYAL-2 were significantly increased (Fig. 2B). The restoring effect of hydrangenol $(1.5,3$, or $6 \mu \mathrm{M})$ on UVBinduced increase of HYAL-1 and HYAL-2 mRNA expression was superior to its effect on HAS-2 mRNA expression. Therefore, hydrangenol might increase HA production by suppressing the degradation of HA in UVB-irradiated cells.

UVB irradiation leads to skin inflammatory responses by increasing pro-inflammatory cytokines, consequently accelerating MMPs expression and collagen decomposition. ${ }^{25)} \mathrm{UVB}$ - induced elevation of COX-2 is closely linked to inflammation and cancer in skin. ${ }^{26,27)}$ Thus, preventing inflammation is another important strategy to protect skin against photoaging. To determine the anti-inflammatory effect of hydrangenol on skin fibroblasts, inhibitory effects of hydrangenol on UVBinduced COX-2, IL-6, IL-8, and IL-1 $\beta$ mRNA expression levels were investigated using qRT-PCR. As shown in Figs. $2 \mathrm{C}$, D, hydrangenol $(1.5,3$, or $6 \mu \mathrm{M})$ significantly suppressed these inflammatory mediators, suggesting that hydrangenol might have anti-inflammatory potential in UVB-irradiated Hs68 fibroblasts.

UVB-induced ROS is an initial pathogenic molecule that causes oxidative stress, skin aging-related gene expression, and subsequent damage to the skin. ${ }^{5)}$ After exposing the cells to UVB, we evaluated the anti-oxidant properties of hydrangenol in $0.5,1,2,4,12$, or $24 \mathrm{~h}$ by cellular ROS staining with $\mathrm{H}_{2}$ DCFDA. As shown in Fig. 3, UVB-induced ROS production increased in a typical cyclic pattern in Hs68 fibroblasts. However, hydrangenol $(6 \mu \mathrm{M})$ significantly reduced ROS production in the cycle in which ROS was increased $(0.5,2$, 4,12 , or $24 \mathrm{~h}$ ). Our data indicate that hydrangenol plays a defensive role against UVB-induced oxidative stress.

UVB-induced ROS activates the signal transduction pathways such as mitogen-activated protein kinase (MAPK), activator protein 1 (AP-1), nuclear factor-kappa B (NF- $\kappa \mathrm{B})$, and janus kinase $(\mathrm{JAK})$ /signal transduction and activation of 
transcription 1 (STAT1). ${ }^{5)}$ AP-1 is composed of homodimers of Jun proteins or heterodimers of Jun-Fos proteins. Its activity is regulated by both expression and phosphorylation of AP-1 proteins. To determine whether hydrangenol could sup-

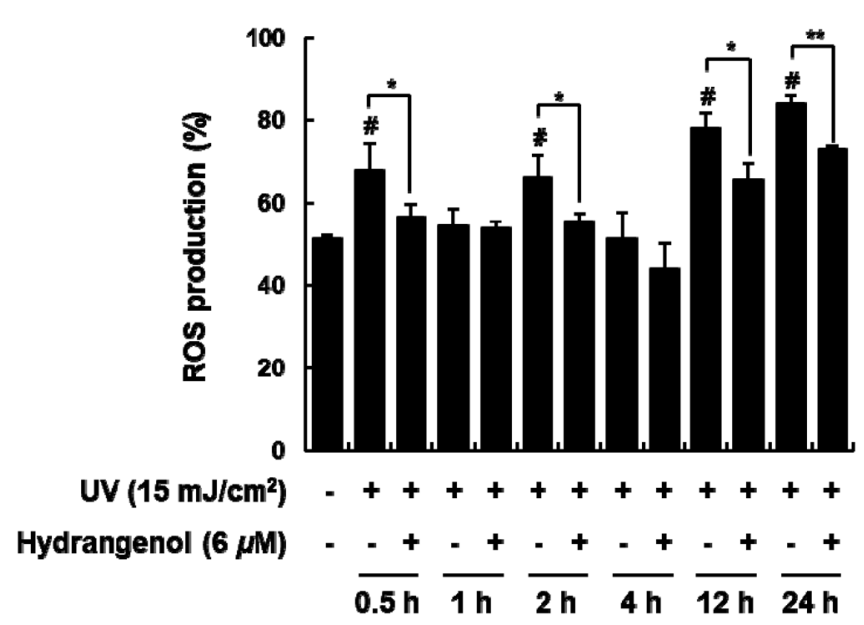

Fig. 3. Hydrangenol Suppressed Intracellular ROS in UVB-Irradiated Hs68 Cells

Following UVB irradiation, cells were treated with hydrangenol for the indicated time and further incubated with $\mathrm{H}_{2}$ DCFDA for $30 \mathrm{~min}$. The fluorescence signal was analyzed using flow cytometry. Data are presented as means \pm S.D.s of three independent experiments. ${ }^{\#} p<0.05 v s$. the control cells; ${ }^{*} p<0.05,{ }^{*} p<0.01 v s$. UVB-exposed cells.

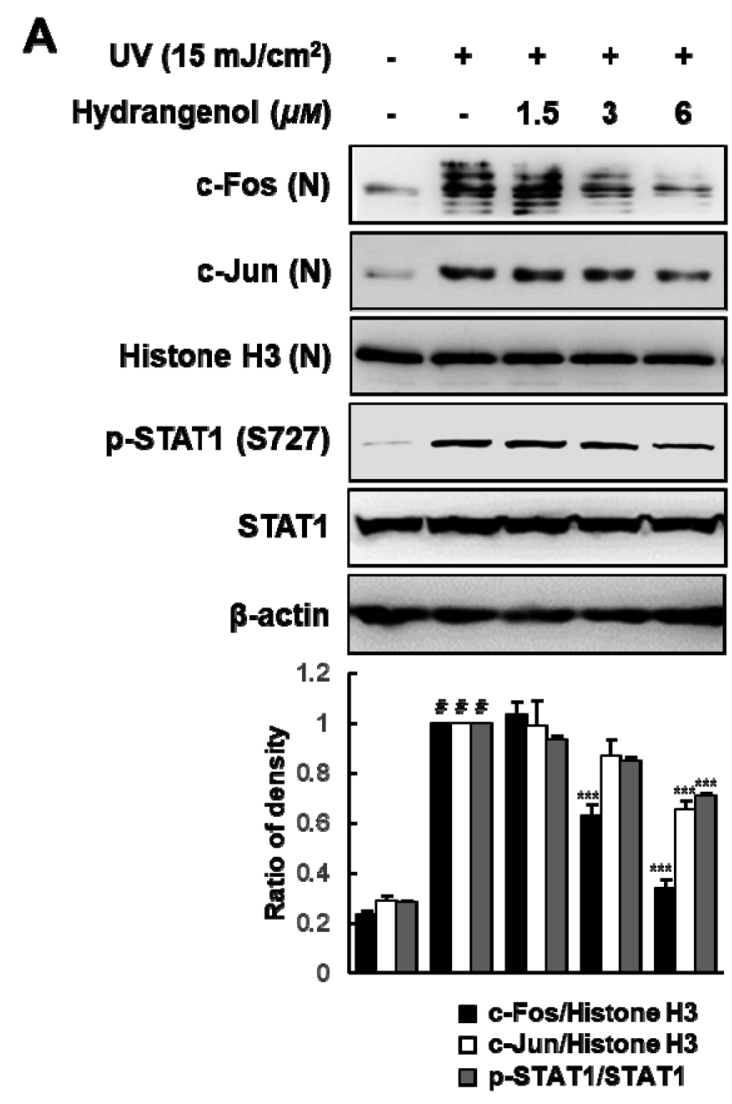

press the UVB-induced AP-1 activation, we determined the accumulation of c-Fos and c-Jun in a nuclear fraction from hydrangenol $(1.5,3$, or $6 \mu \mathrm{M})$-treated Hs68 fibroblasts. Western blot analysis showed that hydrangenol significantly decreased UVB-induced nuclear expression of c-Fos and c-Jun, demonstrating hydrangenol could inhibit UVB-induced AP-1 activation (Fig. 4A). UVB exposure also leads to phosphorylation of STAT1 at Ser727 which in turn enhances its transcriptional activity. ${ }^{28)}$ As shown in Fig. 4A, UVB-induced phosphorylation of STAT1 (Ser727) was diminished by hydrangenol, although total expression of STAT1 was not changed by either UVB or UVB plus hydrangenol. These results suggest that the inhibitory activity of hydrangenol on UVB-induced agingrelated genes such as MMPs, HYALs, and pro-inflammatory mediators might be due to inactivation of AP-1 and STAT1 signaling.

MAPKs including p38, c-Jun N-terminal kinases (JNK), and extracellular signal-regulated kinase (ERK) have been accepted as the targets for chemoprevention of skin disease, given that they are pivotal regulation factors for UVB-induced skin aging by activation several skin aging-related transcription factors. ${ }^{28,29)}$ Therefore, we assessed the phosphorylation rate of $\mathrm{p} 38, \mathrm{JNK}$, and ERK by Western blot analysis, and the results showed that hydrangenol decreased UVB-induced p38 and ERK phosphorylation. No changes in phosphorylation of JNK and total expression of p38, JNK, and ERK were ob-

B

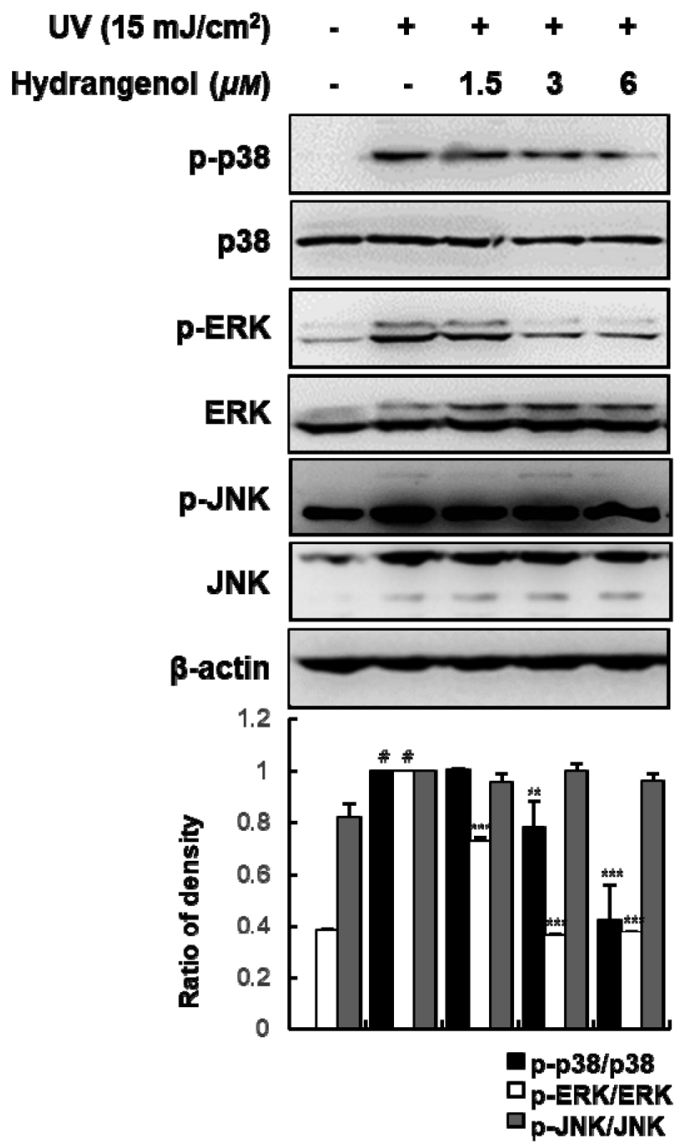

Fig. 4. Effects of Hydrangenol on UVB-Induced Activation of AP-1, STAT1, and MAPKs in Hs68 Cells

(A and B) Nuclear proteins (N) or whole proteins were isolated from cells treated with hydrangenol for $4 \mathrm{~h}$ after UVB exposure. Proteins were detected using specific antibodies for p-cFos, cFos, p-cJun, cJun, p-p38, p38, p-ERK, ERK, p-JNK, and JNK. Histone H3 or $\beta$-actin were used as internal controls for nuclear or whole extraction, respectively. ${ }^{\sharp} p<0.05$ vs. the control cells; $* * p<0.01, * * * p<0.001$ vs. UVB-exposed cells. 
served after treatment with hydrangenol (Fig. 4B). It has been well-described that p38 and ERK can increase the transactivation and stabilization of c-Fos and c-Jun by inducing their expression and phosphorylation and can consequently result in the AP-1 activation. ${ }^{30-32)}$ Moreover, inhibition of p38 or ERK by specific inhibitors or dominant negative mutant can prevent UVB-induced phosphorylation of STAT1, suggesting that p38 and ERK may play a potent role in STAT1-mediated skin inflammatory responses. ${ }^{28)}$ Taken together, our data suggest that hydrangenol can suppress UVB-induced AP-1 and STAT1 activation via interfering with $\mathrm{p} 38$ and ERK-regulated pathway.

In the present study, ten compounds were isolated from $H$. serrata leaves and their protective effects on UVB-induced cell viability, pro-collagen type I, MMP1, and HA were evaluated in Hs68 fibroblasts. Hydrangenol, thunberginol A, thunberginol $\mathrm{C}, 2,3,4^{\prime}$-trihydroxystilbene, thunberginol $\mathrm{F}$, quercetin-xylo-gluco showed preventive activities against the reduced cell viability and the decreased production of procollagen type I and MMP-1. Hydrangenol was the most potent one for HA induction. Hydrangenol restored the production of pro-collagen type I and HA by inhibiting expression levels of MMP-1/-3 and HYAL-1/-2. Hydrangenol also suppressed UVB-induced inflammatory mediators, including COX-2, IL-6, IL-8, and IL-1 $\beta$. Furthermore, hydrangenol suppressed the UVB-induced activation of p38, ERK, AP-1, and STAT1 signaling. Our data indicate that hydrangenol is a valuable skin protective constituent against UVB-induced skin damage. These results may contribute to the understanding of the biological activities of $H$. serrata. It also provides a possible application of $H$. serrata as a beneficial natural anti-photoaging agent.

Acknowledgments This work was supported by Korea Institute of Planning and Evaluation for Technology in Food, Agriculture, Forestry and Fisheries (IPET) through High Value-added Food Technology Development Program, funded by Ministry of Agriculture, Food and Rural Affairs (MAFRA) (117070-03).

Conflict of Interest The authors declare no conflict of interest.

Supplementary Materials The online version of this article contains supplementary materials.

\section{REFERENCES}

1) Watt FM, Fujiwara H. Cell-extracellular matrix interactions in normal and diseased skin. Cold Spring Harb. Perspect. Biol., 3, a005124 (2011).

2) Quan T, Fisher GJ. Role of age-associated alterations of the dermal extracellular matrix microenvironment in human skin aging: a mini-review. Gerontology, 61, 427-434 (2015).

3) Fang CL, Huang LH, Tsai HY, Chang HI. Dermal lipogenesis inhibits adiponectin production in human dermal fibroblasts while exogenous adiponectin administration prevents against UVA-induced dermal matrix degradation in human skin. Int. J. Mol. Sci., 17, 1129 (2016).

4) Binic I, Lazarevic V, Ljubenovic M, Mojsa J, Sokolovic D. Skin ageing: natural weapons and strategies. Evid. Based Complement. Alternat. Med., 2013, 827248 (2013).

5) Bosch R, Philips N, Suarez-Perez JA, Juarranz A, Devmurari A,
Chalensouk-Khaosaat J, Gonzalez S. Mechanisms of photoaging and cutaneous photocarcinogenesis, and photoprotective strategies with phytochemicals. Antioxidants (Basel), 4, 248-268 (2015).

6) Bae JY, Lim SS, Kim SJ, Choi JS, Park J, Ju SM, Han SJ, Kang IJ, Kang YH. Bog blueberry anthocyanins alleviate photoaging in ultraviolet-B irradiation-induced human dermal fibroblasts. Mol. Nutr. Food Res., 53, 726-738 (2009).

7) Jung CH, Kim Y, Kim MS, Lee S, Yoo SH. The establishment of efficient bioconversion, extraction, and isolation processes for the production of phyllodulcin, a potential high intensity sweetener, from sweet hydrangea leaves (Hydrangea macrophylla Thunbergii). Phytochem. Anal., 27, 140-147 (2016).

8) Dilshara MG, Jayasooriya RG, Lee S, Jeong JB, Seo YT, Choi YH, Jeong JW, Jang YP, Jeong YK, Kim GY. Water extract of processed Hydrangea macrophylla (Thunb.) Ser. leaf attenuates the expression of pro-inflammatory mediators by suppressing Akt-mediated NF-kappaB activation. Environ. Toxicol. Pharmacol., 35, 311-319 (2013).

9) Nakagiri R, Hashizume E, Kayahashi S, Sakai Y, Kamiya T. Suppression by hydrangeae dulcis folium of D-galactosamine-induced liver injury in vitro and in vivo. Biosci. Biotechnol. Biochem., 67, 2641-2643 (2003).

10) Ishih A, Ikeya C, Yanoh M, Takezoe H, Miyase T, Terada M. A potent antimalarial activity of Hydrangea macrophylla var. Otaksa leaf extract against Plasmodium yoelii 17XL in mice. Parasitol. Int., 50, 33-39 (2001).

11) Hashimoto T, Tori M, Asakawa Y. Three dihydroisocoumarin glucosides from Hydrangea macrophylla subsp. serrata. Phytochemistry, 26, 3323-3330 (1987).

12) Uesato $S$, Takeda $Y$, Hashimoto $T$, Uobe $K$, Inouye $H$, Taguchi $H$, Endo T. Studies on monoterpene glucosides and related natural products Part 51*. Absolute structures of hydrangenosides A, B, C, D, E, F, and G. Novel type secoiridoid glucosides from two hydrangea plants*. Helv. Chim. Acta, 67, 2111-2127 (1984).

13) Ko GS, Leon US. Korea wild flower. Iljin Publ. Co., Seoul, Korea (2003).

14) Lee JS, Won HS, Kim HJ, Young LN. Effects of cutting period and IBA, NAA, Rooton on the rooting of Hydrangea serrata. J. People Plants Environ., 10, 131-134 (2007).

15) Ahn YH, Lee TJ. Encyclopedia of Korea native plants. Tree of life Publ. Co., Seoul, Korea (1997).

16) Bae JY, Choi JS, Choi YJ, Shin SY, Kang SW, Han SJ, Kang YH. (-)Epigallocatechin gallate hampers collagen destruction and collagenase activation in ultraviolet-B-irradiated human dermal fibroblasts: involvement of mitogen-activated protein kinase. Food Chem. Toxicol., 46, 1298-1307 (2008).

17) Zouboulis CC, Makrantonaki E. Clinical aspects and molecular diagnostics of skin aging. Clin. Dermatol., 29, 3-14 (2011).

18) Argyropoulos AJ, Robichaud P, Balimunkwe RM, Fisher GJ, Hammerberg C, Yan Y, Quan T. Alterations of dermal connective tissue collagen in diabetes: molecular basis of aged-appearing skin. PLOS ONE, 11, e0153806 (2016).

19) DeLeon-Pennell KY, Meschiari CA, Jung M, Lindsey ML. Matrix metalloproteinases in myocardial infarction and heart failure. Prog. Mol. Biol. Transl. Sci., 147, 75-100 (2017).

20) Park MJ, Bae YS. Fermented Acanthopanax koreanum root extract reduces UVB- and $\mathrm{H}_{2} \mathrm{O}_{2}$-induced senescence in human skin fibroblast cells. J. Microbiol. Biotechnol., 26, 1224-1233 (2016).

21) Manuskiatti W, Maibach HI. Hyaluronic acid and skin: wound healing and aging. Int. J. Dermatol., 35, 539-544 (1996).

22) Dai G, Freudenberger T, Zipper P, Melchior A, Grether-Beck S, Rabausch B, de Groot J, Twarock S, Hanenberg H, Homey B, Krutmann J, Reifenberger J, Fischer JW. Chronic ultraviolet B irradiation causes loss of hyaluronic acid from mouse dermis because of down-regulation of hyaluronic acid synthases. Am. J. Pathol., 171, 1451-1461 (2007). 
23) Stern R. Complicated hyaluronan patterns in skin: enlightenment by UVB? J. Invest. Dermatol., 127, 512-513 (2007).

24) Röck K, Grandoch M, Majora M, Krutmann J, Fischer JW. Collagen fragments inhibit hyaluronan synthesis in skin fibroblasts in response to ultraviolet B (UVB): new insights into mechanisms of matrix remodeling. J. Biol. Chem., 286, 18268-18276 (2011).

25) Kuo YH, Wu PY, Chen CW, Lin P, Wen KC, Lin CY, Chiang HM. $\mathrm{N}$-(4-Bromophenethyl) caffeamide protects skin from UVB-induced inflammation through MAPK/IL-6/NF-kappaB-dependent signaling in human skin fibroblasts and hairless mouse skin. Molecules, 22, 1639 (2017)

26) Kim SB, Kim JE, Kang OH, Mun SH, Seo YS, Kang DH, Yang DW, Ryu SY, Lee YM, Kwon DY. Protective effect of ixerisoside A against UVB-induced pro-inflammatory cytokine production in human keratinocytes. Int. J. Mol. Med., 35, 1411-1418 (2015).

27) Prasad R, Katiyar SK. Prostaglandin E2 promotes UV radiationinduced immune suppression through DNA hypermethylation. Neoplasia, 15, 795-804 (2013).
28) Zykova TA, Zhang Y, Zhu F, Bode AM, Dong Z. The signal transduction networks required for phosphorylation of STAT1 at Ser727 in mouse epidermal JB6 cells in the UVB response and inhibitory mechanisms of tea polyphenols. Carcinogenesis, 26, 331-342 (2005).

29) Bachelor MA, Bowden GT. UVA-mediated activation of signaling pathways involved in skin tumor promotion and progression. Semin. Cancer Biol., 14, 131-138 (2004).

30) Iwatsuki M, Inageda K, Matsuoka M. Cadmium induces phosphorylation and stabilization of c-Fos in HK-2 renal proximal tubular cells. Toxicol. Appl. Pharmacol., 251, 209-216 (2011).

31) Loesch M, Zhi HY, Hou SW, Qi XM, Li RS, Basir Z, Iftner T, Cuenda A, Chen G. p38 $\gamma$ MAPK cooperates with c-Jun in transactivating matrix metalloproteinase 9. J. Biol. Chem., 285, 1514915158 (2010).

32) Deng Z, Sui G, Rosa PM, Zhao W. Radiation-induced c-Jun activation depends on MEK1-ERK1/2 signaling pathway in microglial cells. PLOS ONE, 7, e36739 (2012). 